пострадавших от правоохранительного произвола лиц.

\section{Список литературы:}

1. Конституция РФ (принята на всенародном голосовании 12 декабря 1993 года) (с учетом поправок, внесенными Законами РФ о поправках к Конституции РФ № 6-ФКЗ от 30 декабря 2008 г., № 7-ФКЗ от 30 декабря 2008 г., № 2-ФКЗ от 05 февраля 2014 г., № 11-ФКЗ от 21 июля 2014 г.) // Российская газета. 2009. 21 июля.

2. Гражданский кодекс РФ (часть первая) от 30 ноября 1994 г. № 51-Ф3 (в ред. от 29 июля 2019 г.) // С3 РФ. 1994. № 32. Ст. 3301.

3. Уголовно-процессуальный кодекс РФ от 18 декабря 2001 г. № 174-Ф3 (в ред. от 4 ноября 2019 г.) // СЗ РФ. 2001. № 52 (часть I). Ст. 4921.

4. Указание Генпрокуратуры России от 03 июля 2013 г. № 267/12 «О порядке реализации положений части 1 статьи 136 Уголовнопроцессуального кодекса Российской Федерации» // Законность. 2013. № 8.

5. Алистархов В. Проблемы доказывания размера компенсации за моральный вред // Управление персоналом. 2014.№ 2. С. 55-59.

6. Малеина М.Н. Личные неимущественные права граждан: понятие, осуществление, защита. М.: М3 Пресс, 2001. 244 с.

7. Подопригора А.А. Некоторые проблемы уголовно-процессуальной регламентации возмещения вреда лицу, незаконно или необоснованно подвергнутому уголовному преследованию или осуждению // Академический вестник Ростовского филиала Российской таможенной академии. 2018. № 3 (32). С. 62-68.

8. Расаева Х.A. Институт реабилитации в уголовном процессе: проблемы применения //
Вестник РГГУ. Серия: Экономика. Управление. Право. 2019. № 1. С. 122-134.

9. Табунщиков А.Т. Компенсация морального вреда в России и за рубежом: многоаспектность проблемы // Научные ведомости Белгородского государственного университета. Серия «Философия, социология, право». 2009. Т. 57. № 7. С. 146-151

10. Постановление Пленума Верховного Суда РФ № 10 от 20 декабря 1994 г. «Некоторые вопросы применения законодательства о компенсации морального вреда» (в ред. от 6 февраля 2007 г.) // Бюллетень Верховного Суда РФ. 1995. № 3.

11. Постановление Пленума Верховного Суда РФ от 29 ноября 2011 г. № 17 «О практике применения судами норм главы 18 Уголовнопроцессуального кодекса Российской Федерации, регламентирующих реабилитацию в уголовном судопроизводстве» (в ред. от 2 апреля 2013 г.) // Бюллетень Верховного Суда Российской Федерации. 2012. №. 1.

12. Определение Верховного Суда РФ от 14 августа 2018 г. № 78-КГ18-38 // Официальный сайт информационно-правового портала КонсультантПлюс. URL: http://www.consultant.ru.

13. Апелляционное определение судебной коллегии по гражданским делам СанктПетербургского городского суда от 31 августа 2017 г. // Официальный сайт информационно-правового портала КонсультантПлюс. URL: http://www.consultant.ru.

14. Решение Петроградского районного суда Санкт-Петербурга от 12 апреля 2017 г. // Официальный сайт информационно-правового портала КонсультантПлюс. URL: http://www.consultant.ru. ОСВОБОЖДЕНИЯ ОТ УГОЛОВНОЙ ОТВЕТСТВЕННОСТИ.

DOI: $10.31618 /$ ESU.2413-9335.2019.6.69.507

Барсукова Р. $\boldsymbol{A}$

к.ю.н., профессор

Университет «Туран-Астана»

Республика Казахстан (2. Нур-Султан)

Карипова А.И

к.ю.н., дочент

Университет «Туран-Астана»

Республика Казахстан (2. Нур-Султан)

\title{
CONSIDERATION OF FEAR, FEAR AND CONFUSION AS A NECESSARY CONDITION FOR EXEMPTION FROM CRIMINAL LIABILITY.
}

\author{
Barsukova Ritta Anatolievna \\ «Turan-Astana» University, \\ Nur-Sultan, Kazakhstan, \\ «National and international low» department \\ Karipova Assel Yesenkeldyevna \\ «Turan-Astana» Unuversiti, \\ «National and international low» department
}




\section{АННОТАЦИЯ}

В статье рассматривается понятие и признаки необходимой обороны, превышения пределов необходимой обороны, вопросы освобождения лиц от уголовной ответственности, если они превысили пределы необходимой обороны из за страха, испуга или замешательства вызванного общественноопасным посягательством. Превышение пределов необходимой обороны - многоплановая по своему содержанию юридическая категория. Толкование ее законодательной формулировки в значительной мере включает оценочные моменты. Оценочным является, в частности, понятие явности несоответствия характеру и степени общественной опасности посягательства. Для установления явного несоответствия оборонительных действий характеру и степени общественной опасности посягательства, составляющих сущность эксцесса обороны, необходимо установить и объективно выраженное явное, т.е. внешне резкое несоответствие между посягательством и защитой, и субъективно осознаваемое несоответствие между ними - заведомость этого несоответствия для обороняющегося.

Исследуемое несоответствие и в объективном, и в субъективном смысле является в большей степени оценочным, что конечно очень сильно затрудняет реализацию норм, которые связанны с превышением границ необходимой обороны. В связи с чем, необходимо с большой осторожностью и аккуратностью относится к их применению на практике.

\section{ABSTRACT}

The article discusses the concept and signs of necessary defense, exceeding the limits of necessary defense, questions of exemption from criminal liability, if they exceeded the limits of necessary defense because of fear, fear or confusion caused by a socially dangerous attack. Exceeding the limits of necessary defense is a multifaceted in its content legal category. The interpretation of its legislative wording to a large extent includes evaluative points. An appraisal is, in particular, the concept of the manifestation of inconsistency with the nature and degree of public danger of an infringement. In order to establish a clear discrepancy between defensive actions and the nature and degree of public danger of encroachment, which constitute the essence of the excess of defense, it is necessary to establish an objectively expressed explicit, i.e. the outwardly sharp discrepancy between the assault and the defense, and the subjectively recognized discrepancy between them is the deliberate knowledge of this discrepancy for the defender.

The inconsistency under investigation in both the objective and subjective sense is more evaluative, which of course greatly complicates the implementation of the norms that are associated with exceeding the boundaries of the necessary defense. In this connection, it is necessary with great care and accuracy to apply them in practice.

Ключевые слова: необходимая оборона, страх, испуг, замешательство, эксцесс, превышение пределов обороны, оборонительные действия, отражение посягательства, вред, посягательство, общественная опасность, гражданско-правовой деликт, эмоциональное состояние, психиатрическая экспертиза.

Keywords: necessary defense, fear, fear, confusion, excesses, exceeding the limits of defense, defensive actions, repulsing encroachment, harm, encroachment, social danger, civil tort, emotional state, psychiatric examination

Причинение вреда в условиях необходимой обороны рассматривается как общественно полезное, исключающее преступность деяние обстоятельство. Вместе с тем, уголовный закон не исключает наказуемости действий при превышении необходимой обороны. В части третьей ст. 32 УК РК превышением пределов необходимой обороны признается: "правомерная защита личности и прав обороняющегося и других лиц, а также охраняемых законом интересов общества и государства от общественно опасного посягательства, в том числе путем причинения вреда посягающему лицу".

Любое посягательство, особенно если оно совершено внезапно, возбуждает психику человека, выводит его из равновесия и вызывает естественное волнение и замешательство, что может привести к преувеличению опасности. В такой ситуации обороняющийся не всегда адекватно способен оценить обстановку, что нередко ведет к усилению чувства защиты.

Для решения вопроса об уголовной ответственности за деяние, совершенное при превышении пределов необходимой обороны, важное значение имеет закрепленное в УК РК положение об освобождении таких лиц от уголовной ответственности, если они превысили пределы необходимой обороны из-за страха, испуга или замешательства вызванного общественноопасным посягательством .

Возможность освобождения лица от уголовной ответственности при превышении им пределов необходимой обороны законодатель допускает только при наличии определенных условий:

лицо должно превысить пределы необходимой обороны только вследствие страха, испуга или замешательства, а не других причин, например, мести, обиды, самосуда и т.д.;

- указанные причины превышения пределов необходимой обороны должны быть вызваны совершенным общественно опасным посягательством, а не других действий, например, дисциплинарным проступком, административным правонарушением, гражданско-правовым деликтом и т.д.;

- при освобождении от уголовной ответственности в случае превышения пределов необходимой обороны учитываются остальные обстоятельства дела, например: место, время, 
обстановка совершения посягательства, степень и характер защиты, количество посягающих и обороняющихся и т.д.;

- право освобождать от уголовной ответственности при превышении пределов необходимой обороны имеет только суд.

На наш взгляд, под страхом лица, который подвергся нападению и причинил вред нападающему при превышении пределов необходимой обороны следует понимать сильную боязнь лица в связи с совершенным на него посягательством. Эмоциональное состояние лица, отражавшего общественно опасное посягательство, характеризуется внезапным появлением у него чувства страха, вызванного посягательством.

Под испугом следует понимать душевное состояние лица, возникшее в результате внезапного нападения на него.

Под замешательством оборонявшегося лица следует понимать его внезапное смятение, растерянность, беспорядочность его действий, обусловленные страхом, испугом, вызванными теми опасными действиями нападающего, которые в свою очередь являются общественно опасными.

Для решения вопроса о том, находился ли обороняющийся в состоянии страха, испуга или замешательства, повлияло ли такое его состояние на способность оценить свои оборонительные действия и действовать в пределах необходимой обороны, необходимо проведение психологопсихиатрической экспертизы, заключение которой надлежит оценивать в совокупности с другими доказательствами и конкретной обстановкой, сложившейся в результате совершения общественно опасного посягательства и действий по защите от него.

Анализируя вышеизложенное, нужно сказать, что в таких ситуациях в каждом конкретном случае нужно детально выявлять и устанавливать обстоятельства совершения такого деяния, т.к., в зависимости от какой-либо ситуации, которая сложилась на тот момент, в одних случаях лицо, превысившее пределы необходимой обороны в результате страха, испуга, замешательства, может быть освобождено от уголовной ответственности, а в других - нет.

В Уголовном правеоснование для реализации оборонительных мер названо не нападением, а общественно опасным посягательством. И это на наш взгляд, неслучайно, т.к. тем самым закон дает право на защиту против деяний, не имеющих признаков нападения, т.е. попыток причинить ущерб с использованием физической силы.

Существует также мнение, что в содержание побудительных сил лица, превышающего пределы необходимой обороны, может входить не только мотив защиты, но и мотив мести, поэтому основное различие между составами деяний, должно производиться по факту оконченности посягательства со стороны потерпевшего. [1]

Превышение пределов необходимой обороны многоплановая по своему содержанию юридическая категория. Толкование ее законодательной формулировки в значительной мере включает оценочные моменты. Оценочным является, в частности, понятие явности несоответствия характеру и степени общественной опасности посягательства. Для установления явного несоответствия оборонительных действий характеру и степени общественной опасности посягательства, составляющих сущность эксцесса обороны, необходимо установить и объективно выраженное явное, т.е. внешне резкое несоответствие между посягательством и защитой, и субъективно осознаваемое несоответствие между ними - за ведомость этого несоответствия для обороняющегося.

Нужно отметить, что исследуемое несоответствие и в объективном, и в субъективном смысле является в большей степени оценочным, что конечно очень сильно затрудняет реализацию норм, которые связанны с превышением границ необходимой обороны. В связи с чем, необходимо с большой осторожностью и аккуратностью относится к их применению на практике.

Всегда нужно знать, что главное в правильном применении этих понятий является образование адекватных им стандартов (эталонов) оценки, с которыми сравниваются конкретные обстоятельства и ситуации каждого уголовного дела. Это говорит о том, что детализация и стандартизация оценочных понятий способствует гармонизации правоприменительной практики.

Эксцесс обороны проявляется в тех ситуациях, когда лицо которое подвернулось посягательству прибегнул к защите такими средствами и методами, которые могли быть не применены или совершенно очевидно не вызывалось ни характером и опасностью нападения, ни его реальной обстановкой, и без необходимости умышленно причинил нападающему вред.

Так, по мнению Т.Г. Шавгулидзе, вопрос о превышении пределов необходимой обороны можно ставить лишь в тех случаях, когда вред, причиненный посягающему, не был необходим для отражения общественно опасного посягательства. С точки зрения В.И. Ткаченко, превышением пределов необходимой обороны признается причинение посягающему вреда, заведомо и явно не соответствующего тому вреду, который ожидался от его действия. Р.М. Юсупов считает, что превышением пределов необходимой обороны является явное несоответствие последствий использования обороняющимся силы тем последствиям, которые ожидались от действий посягающего. [2]

Совершение преступления в условиях превышения необходимой обороны - деяние относительно менее опасное, чем причинение того же вреда при отсутствии этих условий. В УК РК указывается в качестве смягчающего уголовную ответственность обстоятельства то, что преступление было совершено при нарушении условий правомерности необходимой обороны.

Для определения степени интенсивности нападения существенное значение имеют средства 
нападения и способ, какими осуществляется нападение.

Не всегда лицо, которое применяет право на необходимую оборону в состоянии душевного волнения, которое было вызвано, нападением может точно определить в тот момент характер опасности и тем самым выбрать соразмерные средства защиты. Время нападения это секунды или минуты и поэтому применение оружия или других опасных предметов при посягательстве, в том числе переход оружия от посягавшего к оборонявшемуся, причинение нападавшему сильного вреда, чем предотвращенный вред либо достаточный для отражения нападения, сами по себе не могут свидетельствовать о превышении пределов необходимой обороны. Здесь нужно отметить, что в этих ситуациях не должно быть допущено явного несоответствия защиты характеру и опасности посягательства.

Для правильного решения вопроса о наличии превышения пределов необходимой обороны необходимо учитывать весь комплекс объективных обстоятельств в их совокупности. Придание решающего значения лишь отдельным критериям, формальный подход к оценке действий обороняющегося приводят, как нами было показано выше, к ошибочным выводам при анализе ситуации необходимой обороны и в конечном итоге к необоснованному осуждению лиц, совершивших правомерные оборонительные действия.

Любое превышение пределов необходимой обороны автоматически предполагает состояние такой обороны. И эту точку зрения большинство ученых полностью разделяют. Выражение превышение пределов необходимой обороны заключается в том, что лицо, находящееся в состоянии необходимой обороны, проявляет запредельную оборону и в процессе обороны причиняет нападающему вред, который резко несоразмерный с характером и опасностью посягательства и по своей сути не оправдываемый важностью защищаемого интереса. Выражаясь другими словами, в ходе эксцесса обороны нападающему умышленно причиняется такой тяжкий вред без необходимости, который мог быть и не применен.[3]

Защита выходящая за пределы необходимой обороны означает такую оборону, при которой ее меры и средства, а также интенсивность не соответствуют средствам, интенсивности, опасности и всему характеру нападению. Резкоотличительное несоответствие вреда означает несоответствие ценности, важности, общественного значения интереса защищаемого и интереса, нарушаемого обороной.

Нужно отметить, что нападение и оборона никогда не бывает абсолютно соответствующим друг другу. И уголовный закон предполагает это несоответствие.

При отражении посягательства причиненный посягающему вред может быть равным и даже большим, нежели тот, который причинял или которым угрожал посягающий. Не требуется также полного тождества орудий и средств посягательства орудиям и средствам обороняющегося. При этом закон не допускает явного, не очевидного их несоответствия, так как оно свидетельствует о явном несоответствии опасности посягательства. В случаях, когда защита явно выходит за пределы необходимости, встает вопрос о превышении пределов необходимой обороны [4].

Понятие явного несоответствия относится к оценочным категориям, вопрос о наличии или отсутствии которого решает правоприменитель. И обороняющийся при превышении пределов необходимой обороны должен понимать в таких случаях, что его действия являются излишними, не вызываемыми ни характером, ни опасностью посягательства, ни обстановкой его совершения. Превышение мер защиты только тогда признается преступлением, когда оно явно, очевидно для обороняющегося [4].

В тех случаях, когда посягательство сопряжено с насилием, опасным для жизни обороняющегося или другого лица, либо с непосредственной угрозой такого насилия, превышения пределов необходимой обороны по существу быть не может. В отношении иных преступлений превышение пределов необходимой обороны может иметь место в случаях, когда посягающему умышленно без очевидной необходимости причиняется тяжкий вред. Причинение посягающему чрезмерного вреда по неосторожности ответственности не влечет.

В подобных случаях учитывается, что, будучи в состоянии сильного душевного волнения, вызванного посягательством или его внезапностью, обороняющийся не всегда в состоянии избрать соразмерные меры защиты и причиняет посягающему более тяжкий вред, нежели требовался для пресечения преступления [4].

Особая регламентация порядка и условий применения физической силы, специальных средств и оружия в данном случае вторична. Более того, она должна осуществляться на основе требований уголовно-правового института необходимой обороны и иных обстоятельств, исключающих преступность деяния, а отнюдь не доминировать над ними, имея в целом инструктивный организующий характер. В противном случае сотрудники правоохранительных органов оказываются ограниченными в праве необходимой обороны, что резко снижает потенциал этого важнейшего уголовно-правового института правоохранительной деятельности.

Таким образом, как в обычных условиях, так и в неординарных ситуациях в случае прямой угрозы защищаемым законом интересам правоохранительные органы прямо ограничены в своих полномочиях правом необходимой обороны, пределы которого могут варьироваться в зависимости от урегулированных законами 
обстоятельств, способных повлечь за собой те или иные ограничения прав и свобод.

Законодательная регламентация условий и порядка применения физической силы, специальных средств и оружия сотрудниками правоохранительных структур явно доминирует над общими условиями, вытекающими из принадлежащего каждому субъективного права необходимой обороны. Упоминание же о нем в соответствующих законодательных актах чаще всего относится лишь к ситуациям использования сотрудниками подручных средств. Таким образом, исходный приоритет права необходимой обороны и других обстоятельств, исключающих преступность деяния, в отношении пусть и установленных законом регламентов явно нарушается. Таким образом затушевывание на практике существа трансформации исходных субъективных прав в полномочия органов и сотрудников правоохраны приводит к подмене первых вторыми. И поскольку объективация субъективных прав носит регламентарный характер, то она неизбежно приводит к ограничению права необходимой обороны в отношении сотрудников правоохранительных органов. [5]

Такая ситуация должна расцениваться как противоречащая закону и ущемляющая субъективные права граждан-сотрудников правоохранительных структур, что в силу конституционных положений недопустимо

Очевидно, эффективность реализации института необходимой обороны во многом может быть повышена за счет четкой законодательной регламентации условий правомерности защитных действий, предпринимаемых в целях пресечения общественно опасных посягательств.

Защита путем акта необходимой обороны будет лишь тогда правомерной и исключающей преступность деяния, если она отвечает ряду определенных условий, которые в своей совокупности свидетельствуют о правомерности необходимой обороны.

\section{Список использованных источников}

Косарев А. В. Актуальные проблемы института необходимой обороны. //Автореферат диссертации на соискание ученой степени кандидата юридических наук. Ростов-на-Дону, 2001. - 254 c.

Ткаченко В.И. Необходимая оборона по уголовному праву// М., МГУ, 2000г. - 476 с.

Якубович М.И. Вопросы теории и практики необходимой обороны, М., 2003, С.105-106.; Козак В.Н. Указ.соч., С.81.; Баулин Ю.В. Указ.соч., С.247.

Кондрашова Т.В. Проблемы уголовной ответственности за преступления против жизни, здоровья, половой свободы и половой неприкосновенности. //Екатеринбург, 2000. С. 170.

Кожабаев Ж.О. «Преступное нападение как основание применения необходимой обороны»//Вестник КазНУхабаршы, серия юридическая, №4(52), 2009 - 135-138 с.

\section{ENVIRONMENTAL LAW REFORM: HISTORY AND PROSPECTS}

DOI: $10.31618 /$ ESU.2413-9335.2019.6.69.505

Кыдыров Женис Серикбаевич

Магистрант кафедры международного права юридического факультета Евразийского Национального университета имени Л.Н.Гумилева

\section{АННОТАЦИЯ}

В статье проанализированы понятия «законодательство», его содержание применительно экологической отрасли, субъективные и объективные факторы, способствовавшие становлению экологического законодательства как самостоятельной отрасли в Казахстане. Обобщены наиболее сущностные характеристики экологического законодательства.

\section{ABSTRACT}

The article analyzes the concept of «legislation», its content in relation to the environmental industry, subjective and objective factors that contributed to the formation of environmental legislation as an independent industry in Kazakhstan. The most essential characteristics of environmental legislation are summarized.

Ключевые слова: экологическое право, окружающая природная среда, экологическая безопасность, экологический мониторинг.

Key words: environmental law, environment, environmental safety, environmental monitoring.

Human and civil rights are divided into several groups: personal or civil, economic, political, social, environmental, cultural and information. A special place among these rights is occupied by environmental human rights [1].

Environmental human rights derive from the basic constitutional law of each person, which is enshrined in part 1 of Article 15 of the Constitution of the Republic of Kazakhstan - the right to life.

Article 31 of the Constitution of the Republic of Kazakhstan determines that the state sets the goal of protecting the environment favorable to human life and health [2]. This means that the state guarantees a person living in normal conditions that meet the requirements of standards and requires that everyone comply with the requirements for environmental protection and protection.

The environmental rights of citizens are enshrined in article 13 of the Environmental Code of the Republic of Kazakhstan. So, the basic environmental rights are: the right to an environment favorable to their life and health; the right to establish public associations and 